\title{
Dating the Sea of Marmara Sediments by a Uniform Mixing Model
}

\author{
A. Gökmen, M. Yıldız
}

Department of Chemistry, Middle East Technical University, 06531 Ankara, Turkey

\section{H. N. Erten}

Department of Chemistry, Bilkent University, 06533 Ankara, Turkey

$\&$

\section{Salihoğlu}

Institute of Marine Sciences, Middle East Technical University, P.K. 28, Erdemli, İçel, 33731 Turkey

(Received 20 June 1994; accepted 9 November 1995)

\section{$A B S T R A C T$}

The sedimentation rates and ${ }^{210} \mathrm{~Pb}$ fluxes on sediment surfaces were measured in the north, northwestern and southwestern parts of the Sea of Marmara. Each core had varying thickness of constant ${ }^{210} \mathrm{~Pb}$ activity regions followed by a decreasing part with sediment depth. The sedimentation rates of the samples collected from the Bosporus and the Dardanelles could not be analysed due to the homogenization of activity in the strong currents of these straits. A uniform mixing model is proposed for the simultaneous analysis of sedimentation rates, ${ }^{210} \mathrm{~Pb}$ fluxes and mixing depths from the experimental data. In this model, the parameters were obtained by minimizing the multi-dimensional parameter space using a grid search algorithm. The ${ }^{210} \mathrm{~Pb}$ fluxes were found to be about $0.048 \mathrm{~Bq}^{-2}$ year ${ }^{-1}$ for all sampling sites. The mass sedimentation rates were 0.19 and $0.073 \mathrm{~g} \mathrm{~cm}^{-2}$ year-1 at the shelves of the Bosporus and the Dardanelles and 0.055 and $0.064 \mathrm{~g} \mathrm{~cm}^{-2}$ year ${ }^{-1}$ in the northwestern and middle northern basins, respectively, of the Sea of Marmara. Copyright (C) 1996 Elsevier Science Limited 


\section{INTRODUCTION}

The Sea of Marmara is an almost totally enclosed depression lying between the Black Sea and Aegean Sea having a surface area of approximately $11500 \mathrm{~km}^{2}$ and a total volume of $3378 \mathrm{~km}^{3}$. These two seas are connected by two narrow, shallow straits, the Bosporus and the Dardanelles. The Bosporus is about $31 \mathrm{~km}$ long and $0.7-3.5 \mathrm{~km}$ wide, with an average depth of $35 \mathrm{~m}$. The Dardanelles channel is longer $(62 \mathrm{~km})$, wider $(1 \cdot 2-7 \mathrm{~km})$ and deeper (average $55 \mathrm{~m})$.

The hydrology of the Sea of Marmara is characterized by a permanent two-layer current, a surface outflow from the Black Sea towards the Mediterranean via the Bosporus, the Sea of Marmara, the Dardanelles and the Aegean Sea, and a bottom inflow from the Aegean Sea toward the Black Sea in the reverse direction (Miller, 1983). This results in a stratified water column: low salinity $(22-25 \%)$ water at the top and saline $(38.5 \%)$ water filling the rest of the basin. An average bottom current velocity is measured around $25 \mathrm{~cm} \mathrm{~s}^{-1}$ reaching a maximum value of $60 \mathrm{~cm} \mathrm{~s}^{-1}$ in the Dardanelles, whereas velocities of $10-20 \mathrm{~cm} \mathrm{~s}^{-1}$ are measured in the Bosporus (Ergin et al., 1991). The high current conditions at the bottom of straights wipes off all fine particles, leaving coarse material there.

In addition to the straits of the Bosporus and Dardanelles, a number of rivers and streams drain into the Marmara basins supplying considerable amounts of sediment, primarily from the south. The annual average concentration of total suspended solids in the Sea of Marmara was estimated by Baştürk et al. (1986). There are several point sources in the Sea of Marmara contributing large amounts of particulate matter. Among these the Bosporus, the Dardanelles and the rivers and streams in the south may be counted as the most significant. Additional material is derived from coastal erosion, particulate matter flux from the atmosphere and biogenic activity within the Marmara Basin. The particle fluxes from these sources are summarized in Table 1 (Ergin et al., 1991). Large varia-

\section{TABLE 1}

Particulate Matter Fluxes in and out of the Sea of Marmara $\left(\times 10^{5}\right.$ tons year $\left.{ }^{-1}\right)$

\begin{tabular}{lcc}
\hline Sources & Influx & Outflux \\
\hline Rivers and streams & $6 \cdot 5$ & \\
Atmosphere & 2 & \\
Particulate organic carbon & $2 \cdot 6$ & \\
Bosporus & $14 \cdot 5$ & 6 \\
Dardanelles & 9 & 17
\end{tabular}


tion of sedimentation rates is expected around the major particulate matter sources, especially around the Bosporus and Dardanelles.

There are a few studies in the literature on the characterization of bottom sediments of the Sea of Marmara. The first published data were on the palyonology of a core from the western Marmara Sea (Koreneva, 1971). The distribution of surficial shelf sediments in the northeastern and southwestern parts of the Sea of Marmara was investigated by Ergin et al. (1991). The radiocarbon dating of the eastern basin sediments of the Sea of Marmara was carried out by Stanley and Blanpied (1980) to study the water exchange between the eastern Mediterranean and the Black Sea in the late Quaternary period. Recently, the sedimentation rate in this basin was determined by the ${ }^{210} \mathrm{~Pb}$ dating method and found to be $0.09 \mathrm{~g} \mathrm{~cm}^{-2}$ year $^{-1}$ (Evans et al., 1989).

Usually, measurement of the surface sedimentation rate using the ${ }^{210} \mathrm{~Pb}$ technique is complicated due to physical and biological mixing of sediments at the top sediment layers. Carpenter et al. (1981) have analysed such data by extrapolating the sediment accumulation line to zero while keeping its slope and total area constant under the original ${ }^{210} \mathrm{~Pb}$ profile.

In this study, the sedimentation rates and ${ }^{210} \mathrm{~Pb}$ fluxes at the sediment surfaces were measured at the north-northwestern and southwestern part of the Sea of Marmara by the ${ }^{210} \mathrm{~Pb}$ technique. The samples used in this work were collected from the north-northwestern and southwestern parts of the Sea of Marmara and the two straits, the Bosporus and the Dardanelles onboard the research ship R/V Knorr using a Soutar Box corer $(50 \times 50 \times 60 \mathrm{~cm})$ on its 1989 cruise. The sampling sites are shown in Fig. 1. The samples M1 and M9 were taken from the Bosporus and Dardanelles, respectively. The samples M2 and M8 are from the southern and northern shelves of the Bosporus and Dardanelles, respectively. These two sites are subject to large particulate matter fluxes from the nearby straits. The last two samples, M5 and M7 were collected from the two eastern basins of the northern Marmara Sea. The water depth, coordinates of sampling sites and sediment thicknesses of cores are given in Table 2.

A constant ${ }^{210} \mathrm{~Pb}$ activity region has often been observed extending to several centimetres below the sediment/water interface in many studies (Erten et al., 1985; Robbins \& Edgington, 1975; Eakins \& Morrison, 1978; Smith \& Walton, 1980). Several mixing models have been developed in order to account for this constant activity region (Guinasso \& Schink, 1975; Robbins \& Edgington, 1975; Robbins et al., 1977; Christensen, 1982). In this study, a novel method, the uniform mixing model, is proposed for the analysis of the ${ }^{210} \mathrm{~Pb}$ activity profiles of cores. The model yields the ${ }^{210} \mathrm{~Pb}$ flux and the depth of constant activity zone at the top of cores besides the sedimentation rate. The sedimentation rates obtained in 


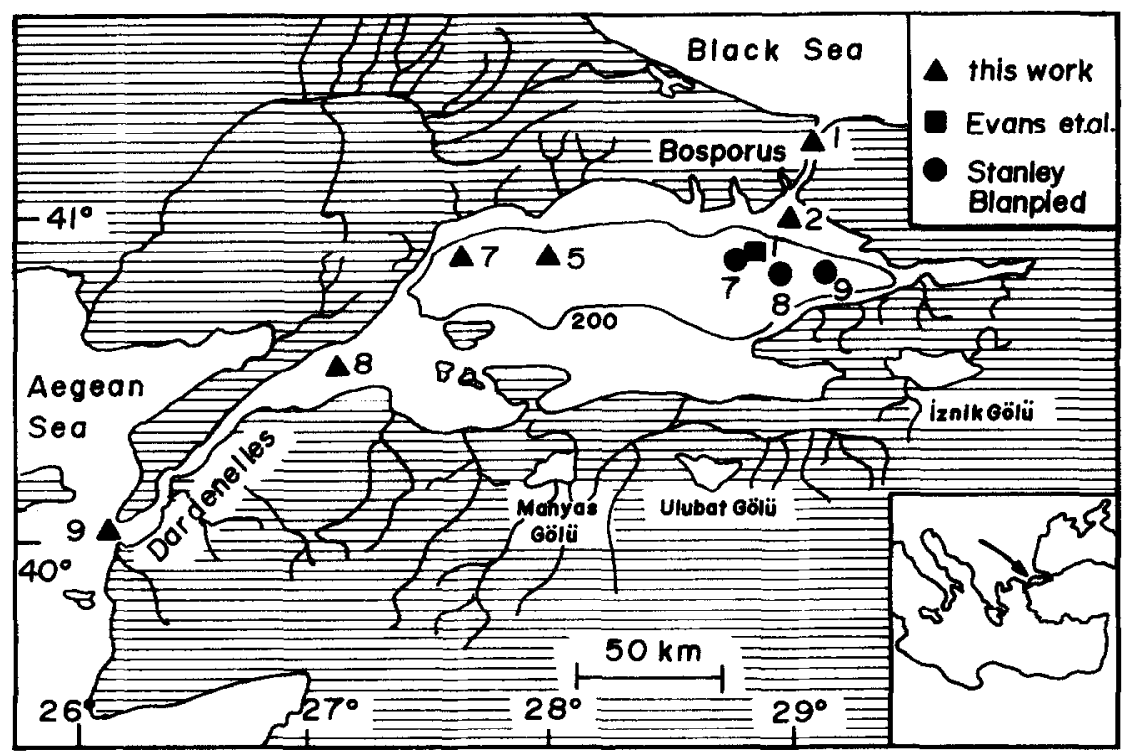

Fig. 1. Sampling sites of the sediment cores recovered from the Sea of Marmara.

this work for the two northwestern basins are compared with the results of Evans et al. (1989) and Stanley and Blanpied (1980). The effect of the two largest point sources of particulate matter, i.e. the Bosporus and Dardanelles, on the sedimentation rate in the Sea of Marmara is also discussed in some detail.

\section{UNIFORM MIXING MODEL}

A characteristic ${ }^{210} \mathrm{~Pb}$ activity curve used in sedimentation rate determination consists of three regions as illustrated in Fig. 2. The first

\section{TABLE 2}

The Water Depth, Location and Sediment Thickness of Cores Used in this Work

\begin{tabular}{ccccc}
\hline Station & $\begin{array}{c}\text { Water } \\
\text { depth }(m)\end{array}$ & $\begin{array}{c}\text { Latitude } \\
(N)\end{array}$ & $\begin{array}{c}\text { Longitude } \\
(E)\end{array}$ & $\begin{array}{c}\text { Sediment } \\
\text { thickness }(\mathrm{cm})\end{array}$ \\
\hline M1 & 54 & $41^{\circ} 11^{\prime} 29^{\prime \prime}$ & $29^{\circ} 05^{\prime} 55^{\prime \prime}$ & 18 \\
M2 & 64 & $40^{\circ} 54^{\prime} 48^{\prime \prime}$ & $28^{\circ} 56^{\prime} 03^{\prime \prime}$ & 46 \\
M5 & 1226 & $40^{\circ} 49^{\prime} 48^{\prime \prime}$ & $27^{\circ} 57^{\prime} 35^{\prime \prime}$ & 54 \\
M7 & 1106 & $40^{\circ} 48^{\prime} 26^{\prime \prime}$ & $27^{\circ} 36^{\prime} 35^{\prime \prime}$ & 58 \\
M8 & 65 & $40^{\circ} 32^{\prime} 02^{\prime \prime}$ & $27^{\circ} 09^{\prime} 37^{\prime \prime}$ & 48 \\
M9 & 74 & $40^{\circ} 01^{\prime} 37^{\prime \prime}$ & $26^{\circ} 15^{\prime} 09^{\prime \prime}$ & 28 \\
\hline
\end{tabular}




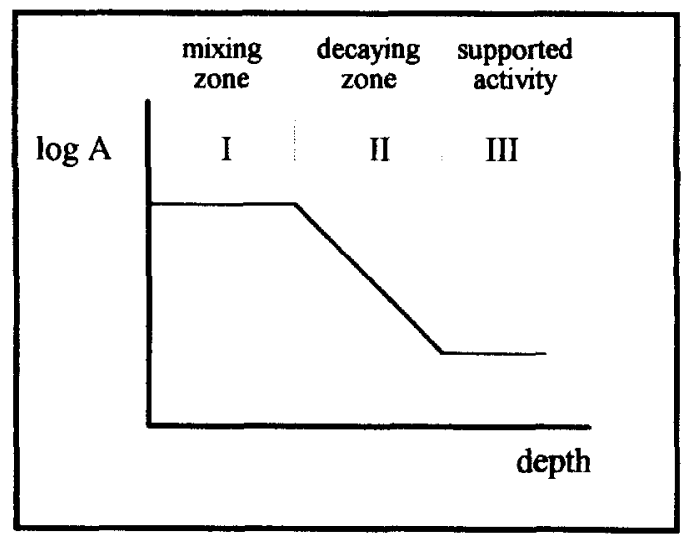

Fig. 2. Illustration of different regions of the ${ }^{210} \mathrm{~Pb}$ activity profile of a typical sediment core.

constant ${ }^{210} \mathrm{~Pb}$ activity region may be due to the biological and physical mixing or the resuspension of ${ }^{210} \mathrm{~Pb}$ at the top layers of sediments. The second region corresponds to the decreasing activity of ${ }^{210} \mathrm{~Pb}$ with depth. The constant activity in the third region is due to ${ }^{226} \mathrm{Ra}$ parent activity coming from the sea floor, the so-called supported ${ }^{210} \mathrm{~Pb}$ activity. Radiochronology studies in the literature usually focus on the determination of sedimentation rates. This information may be obtained easily by a linear least-square fitting to the second region of the activity profile. The uniform mixing model developed in this work is used to compute all of the three parameters: sedimentation rate, ${ }^{210} \mathrm{~Pb}$ flux on sediment surface and the mixing depth at the top sediment layers, simultaneously from the experimental data. The details of the uniform mixing model are given below.

The unsupported ${ }^{210} \mathrm{~Pb}$ activity due to atmospheric fall-out and in situ produced component is obtained by subtracting the constant supported activity (i.e. ${ }^{226} \mathrm{Ra}$-supported ${ }^{210} \mathrm{~Pb}$ ) from the measured total activity. A typical unsupported activity profile of a core, after compaction correction, is plotted as the solid line in Fig. 3. This profile has a constant activity layer from top till the mixing depth, $x_{\mathrm{o}}$, followed by an exponential decay region. In the uniform mixing model the activities are expressed separately for these regions. The mathematical expression for the constant activity region may be obtained from the dashed line given in Fig. 3. This line has the same slope as the decaying part of the solid line in Fig. 3. Moreover, the activity profiles of solid and dashed lines have the same total activity. The unperturbed activity of this dashed line may be given as follows:

$$
A_{\text {up }}(x)=A_{0} \mathrm{e}^{-(\lambda / S) x}
$$




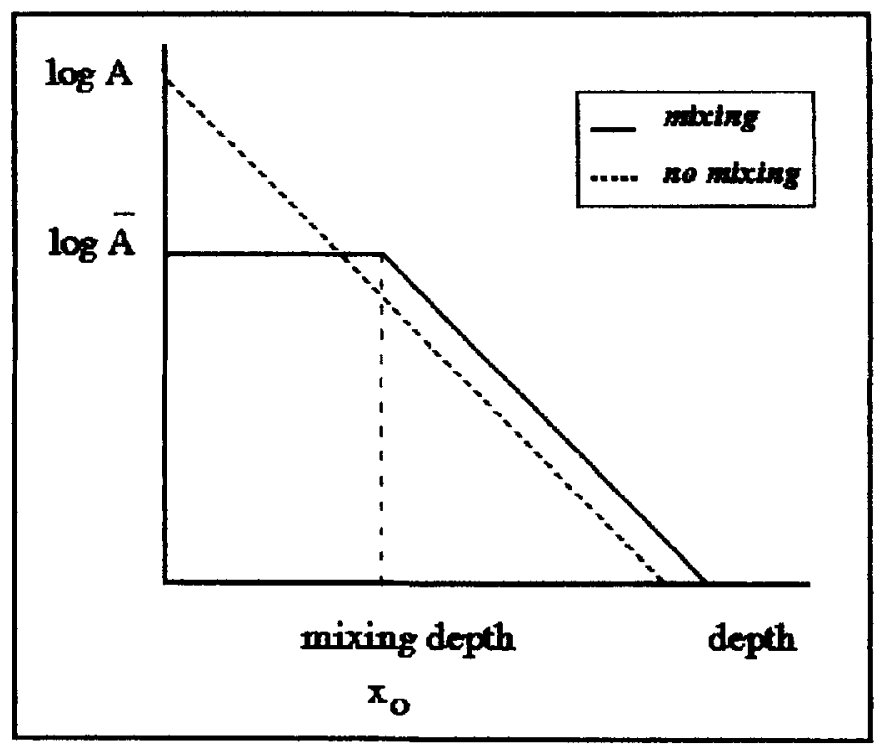

Fig. 3. Illustration of unsupported ${ }^{210} \mathrm{~Pb}$ activity profiles for mixed and unsupported sediment samples.

Here, $\lambda$ is the decay constant of ${ }^{210} \mathrm{~Pb}, S$ is the sedimentation rate and $x$ is the depth of the sediment column. The initial activity, $A_{0}$, is defined as (Robbins \& Edgington, 1975):

$$
A_{0}=\frac{P}{S \rho(1-\phi)}
$$

where $P$ is the total flux of ${ }^{210} \mathrm{~Pb}$ from the atmosphere and in situ produced component, $\rho$ is the density and $\phi$ is the porosity of the sediment.

In most of the activity profiles a flat region is observed due to the physical and/or biological mixing of sediment. In this region the decaying activity of the radioisotope is averaged out to yield a constant value.

Two simple relations were used to describe the perturbed activity profiles. The unsupported activity in the mixing zone (i.e. zone I in Fig. 2) is given as:

$$
A_{x}=\bar{A} \quad \text { if } \quad x \leqslant x_{0}
$$

and the unsupported activity after the mixing zone (i.e. zone II in Fig. 2) is defined as:

$$
A_{x}=\bar{A} \mathrm{e}^{-\lambda\left(x-x_{0}\right) / S} \quad \text { if } x>x_{0}
$$

The value of the average activity, $\bar{A}$, in eqns (3) and (4) may be obtained from the condition that the total activity under the activity profiles of 
mixed and unperturbed core samples, as shown in Fig. 3, is constant. The total activity for an unperturbed activity profile is obtained by integrating eqn (1) from 0 to infinity, which yields:

$$
A_{\text {up }}^{\mathrm{T}}=A_{0} \frac{S}{\lambda}
$$

The total activity for a perturbed activity profile is obtained in two steps: the area under eqn $(3)\left(=\bar{A} x_{\mathrm{o}}\right)$ is added to the area obtained by integrating eqn (4) from $x_{0}$ to infinity, which gives:

$$
A_{x}^{\mathrm{T}}=\bar{A}\left(x_{0}+\frac{S}{\lambda}\right)
$$

The conservation of total activity (i.e. $A_{\mathrm{up}}^{\mathrm{T}}=A_{x}^{\mathrm{T}}$ ) yields the relation:

$$
\bar{A}=A_{0} /\left(1+\frac{x_{0} \lambda}{S}\right)
$$

By substituting eqns (7) and (2) into eqn (4), a nonlinear equation in terms of the fitting parameters, $S, P$ and $x_{0}$ is obtained after the mixing zone, $x_{0}$. Equation (3), which is equivalent to eqn (7), is used for the computation of activities within the mixing zone. The analysis of data is carried out by a nonlinear least-square fitting based upon a grid search algorithm (Bevington, 1969). The error function used in the analysis program utilizes eqn (3) for the computed value of activity if $x<x_{0}$, otherwise eqn (4) is used. The program terminates when the changes in error function is less than $1 \%$.

\section{EXPERIMENTAL}

The recovered cores were cut into 2 -cm sections. The density, $\rho$, and porosity $\phi$, of each section are measured and the results are given in Table 3 . The porosities in each core did not show any significant variation with depth, hence average values are given here. The samples collected from the Bosporus and Dardanelles, M1 and M9 have not been included in the table since the strong mixing in these highly turbulent straits made the data analysis impossible.

The concentration of ${ }^{210} \mathrm{~Pb}$ was measured indirectly by counting the alpha particle activity of its daughter, ${ }^{210} \mathrm{Po}$. Polonium is a volatile element. It was separated from the sediment samples by heating the samples to $600^{\circ} \mathrm{C}$ in an electrically heated Pyrex tube and collecting it over a wetted glass wool. Polonium was then extracted from the glass wool by leaching with an acid solution and self deposited on a silver disk. The 
TABLE 3

The Density and Porosity of Cores

\begin{tabular}{ccc}
\hline Station & Density, $\rho\left(\mathrm{g} \mathrm{cm}^{-3}\right)$ & Porosity, $\phi$ \\
\hline M2 & 2.89 & 0.66 \\
M5 & 2.63 & 0.79 \\
M7 & 2.63 & 0.75 \\
M8 & 2.44 & 0.73 \\
\hline
\end{tabular}

details of the method are given by Erten et al. (1985) and El-Daoushy et al. (1991).

The alpha-particle activity of ${ }^{210} \mathrm{Po}$ was measured with a silicon surface barrier detector (ORTEC, model No. BA-018-300-100) mounted in a vacuum chamber. The detector signal was fed into an ORTEC Model 109A preamplifier and then to a multichannel analyser (Canberra model $35+)$ for recording the alpha particle spectrum. The data were stored in an IBM-XT computer interfaced to the multichannel analyser. Most of the samples were counted for $20000 \mathrm{~s}$ but samples with higher activities were counted for $10000-20000 \mathrm{~s}$.

The extraction and counting efficiencies for ${ }^{210} \mathrm{Po}\left(E_{\alpha}=5.305 \mathrm{MeV}\right)$ is usually determined with another alpha-particle-emitting radioisotope of polonium, ${ }^{208} \mathrm{Po}\left(E_{\alpha}=5.116 \mathrm{MeV}\right)$. However, the ${ }^{208} \mathrm{Po}$ radioisotope was not available in our laboratory. Instead, a standard ${ }^{210} \mathrm{~Pb}$ solution in secular equilibrium with ${ }^{210} \mathrm{Po}$ was used to check the overall efficiency of ${ }^{210} \mathrm{Po}$ deposition/plating. The deposition time of polonium on the silver disk was optimized. The deposition efficiency reached above $90 \%$ after $5 \mathrm{~h}$ of deposition at $90^{\circ} \mathrm{C}$ and staycd constant thercafter.

The detector counting efficiency was determined using a ${ }^{210} \mathrm{~Pb}$ standard solution evaporated to dryness on a silver disk. The detector-sample distance was held at $0.8 \mathrm{~cm}$ to prevent the contamination of detector surface by the volatile polonium which might condense on the detector. The alpha particle counting efficiency was found to be $6.8 \%$ for this assembly.

There are different sources of errors in the ${ }^{210} \mathrm{~Pb}$ flux and sedimentation rate measurements. The total errors in the measured activity of ${ }^{210} \mathrm{~Pb}$ were propagated by adding the squares of the individual errors and found to be between 20 and $50 \%$ including counting errors.

\section{RESULTS}

The experimental parameters, surface ${ }^{210} \mathrm{~Pb}$ flux, mixing depth of sediments and sedimentation rate for sediment cores from the sampling sites 
M2, M5, M7 and M8 were obtained from the experimental data using the uniform mixing model. The experimental activity concentrations are given in Table 4 as a function of sediment thickness.

The program developed in this work for the computation of the three parameters ${ }^{210} \mathrm{~Pb}$ flux, $P$, mixing depth, $x_{0}$, and sedimentation rate, $S$, was written by using a Turbo Pascal compiler. The computation was carried out in three steps. Firstly, the experimental activities were entered and the unsupported activities were computed by subtracting the supported activities (i.e. the constant activity zone in Fig. 2) from the measured activities. In the second step of the computation, the initial values of the three parameters, $P$, $x_{\mathrm{o}}$ and $S$, were estimated. Finally, the optimum values of these parameters were obtained by the grid search algorithm as defined above. The search started with the initial parameters and continued until the change in $\chi^{2}$ was less than $1 \%$. The search for the minimum in the parameter space converged to the optimum values in less than 10 iterations.

The unsupported ${ }^{210} \mathrm{~Pb}$ activities of samples M2, M5, M7 and M8 as computed by the program are plotted in Fig. 4. The errors in the unsupported activities were given within $1 \sigma$.

The constant activity regions in the mixing zone of sediment cores are followed by a decreasing activity region with varying slopes. A steeper slope corresponded to a lower sedimentation rate as given in eqn (1).

The mass sedimentation rate $\omega\left(\mathrm{g} \mathrm{cm}^{-2}\right.$ year $\left.^{-1}\right)$ is related to the linear sedimentation rate, $S$, as follows (Durham \& Joshi, 1984):

$$
\omega\left(\mathrm{g} \mathrm{cm}^{2} \text { year }{ }^{1}\right)=S\left(\mathrm{~cm}_{\text {year }}{ }^{1}\right) \rho\left(\mathrm{g} \mathrm{cm}^{3}\right)(1-\phi)
$$

The results of computations are given in Table 5 .

TABLE 4

Experimental ${ }^{210} \mathrm{~Pb}$ Activities $\left(\mathrm{Bq} \mathrm{g}^{-1}\right.$ ) of Sediment Samples from Sites M2, M5, M7 and M8

\begin{tabular}{|c|c|c|c|c|}
\hline Depth $(\mathrm{cm})$ & $M 2$ & M5 & $M 7$ & $M 8$ \\
\hline $0-2$ & $22-24$ & $0.17 \pm 0.03$ & $0.06 \pm 0.01$ & $0.52 \pm 0.05$ \\
\hline $2-4$ & & $0.15 \pm 0.03$ & & $0.39 \pm 0.04$ \\
\hline $4-6$ & & $0.18 \pm 0.04$ & & $0.37 \pm 0.04$ \\
\hline $6-8$ & & $0.17 \pm 0.04$ & & $0.24 \pm 0.03$ \\
\hline $8-10$ & & $0.14 \pm 0.03$ & & $0.18 \pm 0.03$ \\
\hline $10-12$ & & $0.10 \pm 0.02$ & & $0.14 \pm 0.02$ \\
\hline $12-14$ & & $0.06 \pm 0.01$ & & $0.19 \pm 0.03$ \\
\hline $14-16$ & & $0.10 \pm 0.02$ & & $0.11 \pm 0.02$ \\
\hline $16-18$ & & $0.10 \pm 0.02$ & & $0.12 \pm 0.02$ \\
\hline $18-20$ & & $0.05 \pm 0.01$ & & $0.12 \pm 0.02$ \\
\hline $20-22$ & & $0.04 \pm 0.01$ & & $0 \cdot 10 \pm 0.02$ \\
\hline
\end{tabular}




\section{Activity}

(dpm/g)
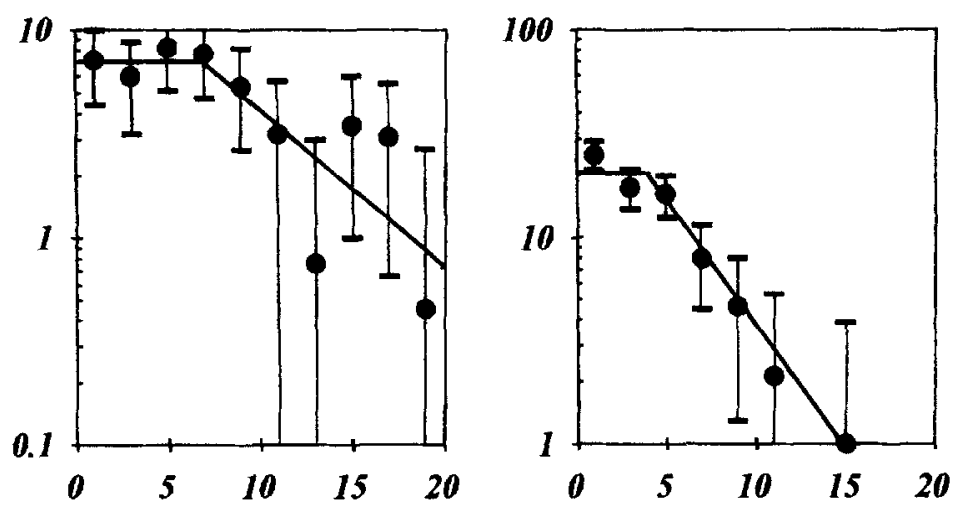

M7

\section{M8}
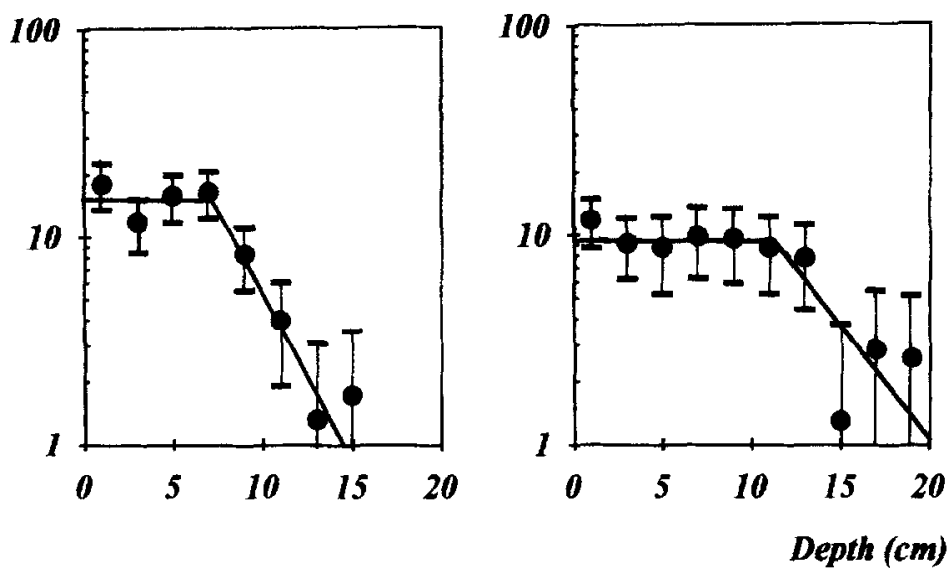

Fig. 4. The activity profiles of sediment cores M2, M5, M7 and M8.

All the ${ }^{210} \mathrm{~Pb}$ fluxes determined for various samples were found to be identical within the uncertainties of measurements. An average ${ }^{210} \mathrm{~Pb}$ flux of $0.048 \pm 0.01 \mathrm{~Bq} \mathrm{~cm}^{-2}$ year $^{-1}$ was found for the Sea of Marmara sediments. The mixing depth of the samples varied between 4 and $11 \mathrm{~cm}$. The mass sedimentation rate was found to be largest, namely $0.19 \mathrm{~g} \mathrm{~cm}^{-2}$ year $^{-1}$, for the samples collected at the southern shelf of Bosporus and lowest, $0.055 \mathrm{~g} \mathrm{~cm}^{-2}$ year $^{-1}$, at the northwestern basin of the Sea of 
TABLE 5

Experimental Parameters, ${ }^{210} \mathrm{~Pb}$ Fluxes, Mixing Depths and Sedimentation Rates for Sediment Core Samples from the Sea of Marmara

\begin{tabular}{|c|c|c|c|c|}
\hline Sample & $\begin{array}{c}\text { Flux }, P \\
\left(B q \mathrm{~cm}^{-2} \text { year }\right.\end{array}$ & $\begin{array}{l}\text { Mixing depth } \\
x_{\mathrm{o}}(\mathrm{cm})\end{array}$ & $\begin{array}{l}\text { Sedimentation } \\
\text { rate, } S\left(\mathrm{~cm}^{-1} \text { year }\right.\end{array}$ & $\begin{array}{l}\text { Mass sedimentation } \\
\text { rate } \omega\left(\mathrm{g} \mathrm{cm}^{-2} \text { year }\right.\end{array}$ \\
\hline M2 & $0.047 \pm 0.008$ & $7 \pm 1$ & $0.19 \pm 0.07$ & $0.19 \pm 0.07$ \\
\hline M5 & $0.046 \pm 0.005$ & $4 \pm 1$ & $0.12 \pm 0.03$ & $0.064 \pm 0.014$ \\
\hline M7 & $0.052 \pm 0.006$ & $7 \pm 1$ & $0.08 \pm 0.02$ & $0.055 \pm 0.014$ \\
\hline M8 & $0.049 \pm 0.007$ & $11 \pm 1$ & $0.11 \pm 0.05$ & $0.073 \pm 0.031$ \\
\hline $\mathrm{E} 1^{a}$ & & 3 & $0.12 \pm 0.02$ & $0.087 \pm 0.012$ \\
\hline
\end{tabular}

${ }^{a}$ Fvans et al. (1989); see Fig. 1.

Marmara. The sedimentation rate found at the mid-northern basin, $0.064 \mathrm{~g} \mathrm{~cm}^{-2}$ year $^{-1}$ (site M5), was slightly smaller than that measured by Evans et al. (1989), $0.087 \mathrm{~g} \mathrm{~cm}^{-2}$ year ${ }^{-1}$, at the eastern basin. The core sampled near the Dardanelles (M8) gave a much lower sedimentation rate, $0.073 \mathrm{~g} \mathrm{~cm}^{-2}$ year $^{-1}$, compared with a similar site near the Bosporus (M2).

The sampling site $\mathrm{M} 2$ is located on the southern part of Bosporus and is subject to the highest particulate matter flux compared to other locations. The amount of particulate matter carried from the Black Sea via the surface currents in the Bosporus towards the Sea of Marmara is 1.5 million tons and a reverse bottom current transfers about 0.6 million tons of particulate matter from the Marmara Sea into the Black Sea annually, as given in Table 1. Thus, the net particulate matter flux into the Sea of Marmara is about 0.9 million tons annually from this source.

The particulate matter flux in the Dardanelles is just the opposite of the Bosporus. Here, 0.9 million tons of particulate matter is carried from the Aegean Sea into the Sea of Marmara by bottom currents and 1.7 million tons of particulate matter is carried out in the reverse direction by surface currents. The net particulate matter outflux in the Dardanelles is about 0.8 million tons annually. The sedimentation rate measured at M8 location was found to be about half of that at M2 due to the above considerations.

The sedimentation rate measured in this work covers the top $15-20 \mathrm{~cm}$ of the cores. Assuming an average sedimentation rate of $0.1 \mathrm{~cm}^{-1} \mathrm{rr}^{-1}$, the ${ }^{210} \mathrm{~Pb}$ activity is expected to die out within the top $10-15 \mathrm{~cm}$. However, the homogenization of the activity within the top layers pushes the decaying ${ }^{210} \mathrm{~Pb}$ activity deeper into the sediment core (see Fig. 3).

Some sediment samples collected from the eastern basin of the Sea of Marmara as shown in Fig. 1 had been dated using the ${ }^{14} \mathrm{C}\left(t_{\frac{1}{2}}=5730\right.$ year $)$ technique by Stanley and Blanpied (1980). The samples collected from the site G8 in that work dated as 4700 years at a depth of $100-110 \mathrm{~cm}$. This 
would roughly correspond to sedimentation rates of about $0.01 \mathrm{~cm} \mathrm{year}^{-1}$ at the top $60 \mathrm{~cm}$ and $0.07 \mathrm{~cm}_{\text {year }}^{-1}$ between 60 and $110 \mathrm{~cm}$. The latter sedimentation rate, derived from the difference of two radiocarbon datings, is comparable to our findings. However, the former rate given in that work is nearly a factor of 10 lower than the recent sedimentation rates. The low sedimentation rate estimates from the radiocarbon dating of Stanley and Blanpied's data was criticized by Evans et al., and it was attributed to the silty composition of the sediments and the long residence time of organic carbon in the sea water. The radiocarbon dates could lead to errors in age estimates of up to about 2000 years (Calvert et al., 1987).

The geological composition of the G7, G8 and G9 cores of Stanley and Blanpied at the top 63,47 and $38 \mathrm{~cm}$ sections, respectively, were very similar to those of Evans et al. recovered at a site between G7 and G8. Assuming similar constant sedimentation rates in the last 1000 years in sites G7 and E1, we estimated the sedimentation rates at G7, G8 and G9 as $0.087 \mathrm{~g} \mathrm{~cm}^{-2}$ year $^{-1}$ (Evans et al., 1989), 0.065 and $0.052 \mathrm{~g} \mathrm{~cm}^{-2}$ year $^{-1}$, respectively. The latter two values were obtained by scaling the sedimentation rate at $\mathrm{G} 7$ with respect to the thicknesses of the top layers of these cores with similar geological structure.

The mass sedimentation rate, $\omega$, measured at sampling sites M2, M5, M7 and M8 in this work, El of Evans et al. and the estimated mass sedimentation rates at sampling sites G7, G8 and G9 of Blanpied and Stanley are shown in Fig. 5. The locations of these sites have already been shown in Fig. 1. Here, the highest sedimentation rate at the sampling site M2 can be attributed to the large particulate matter flux from the Bosporus. As the distance from the M2 location increases, the sedimentation rates

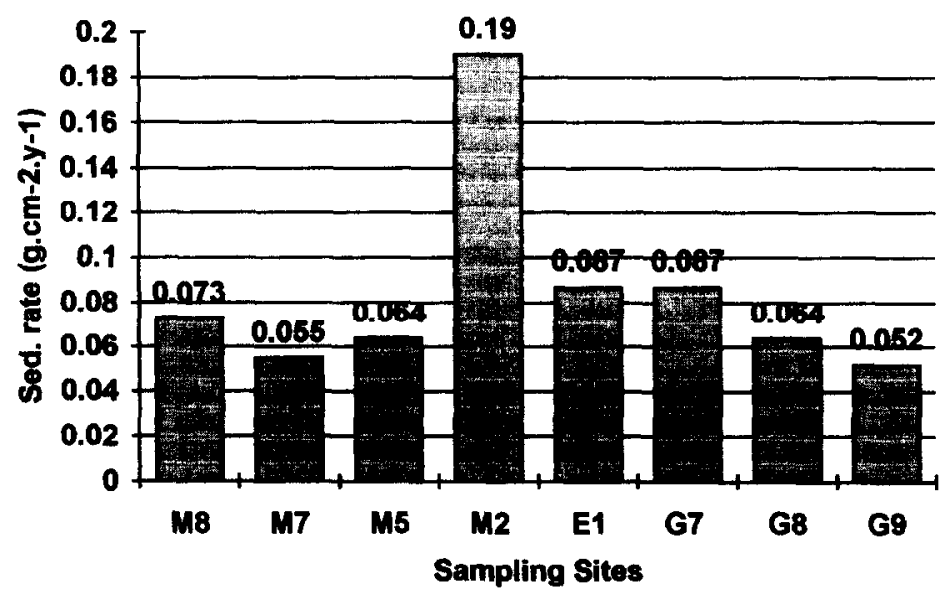

Fig. 5. Mass sedimentation rates at sampling sites shown in Fig. 1. 
decrease at the three northern basin sites of the Sea of Marmara. The lower particulate flux in the Dardanelles as compared with the Bosporus is reflected in the lower sedimentation rate at M8.

\section{REFERENCES}

Baştürk, O., Saydam, A. C. , Salihoglu, I. \& Yilmaz, A. (1986). Oceanography by the Turkish Straits, I.; Oceanography by the Turkish Straits, III: Health of the straits; II: Chemical and environmental aspects of the Sea of Marmara. Institute of Marine Science Institute, METU, İçel, Turkey.

Bevington, P. R. (1969). Data Reduction and Error Analysis for the Physical Sciences. McGraw-Hill, New York.

Calvert, S. E., Vogl, J. S. \& Southon, J. R. (1987). Carbon accumulation rates and the origin of Holocene sapropel in the Black Sea. Geology, 15, 918-21.

Carpenter, R., Bennett, J. T. \& Peterson, M. L. (1981). ${ }^{210} \mathrm{~Pb}$ activities in and fluxes to sediments of the Washington continental slope and shelf. Geochim. Cosmochim. Acta, 45, 1155-72.

Christensen,E. R. (1982). A model for radionuclides in sediments influenced by mixing and compaction. J. Geophys. Res., 87, 566-72.

Durham, V. R. \& Joshi, S. R. (1984). Quaternary Dating Methods. Elsevier Science, Amsterdam.

Eakins, J. D. \& Morrison, R. T. (1978). A new procedure for the determination of lead-210 in lake and marine sediments. Int. J. Appl. Rad. Isotopes, 29, $531-6$.

El-Daoushy, F., Olsson, K. \& Garcia-Tenorio, R. (1991). Accuracies in Po-210 determination for lead-210 dating. Hydrobiologia, 214, 43-52.

Ergin, M., Bodur, M. N. \& Ediger, V. (1991). Distribution of surficial shelf sediments in the northeastern and southwestern parts of the Sea of Marmara: strait and canyon regimes of the Dardanelles and Bosporus. Marine Geology, 96, 313-40.

Erten, H. N., von Gunten, H. R., Rössler, E. \& Sturm, M. (1985). Dating of sediments from Lake Zurich (Switzerland) with ${ }^{210} \mathrm{~Pb}$ and ${ }^{137} \mathrm{Cs}$. Schweiz. Z. Hydrol., 47(1), 5-11.

Evans, G., Erten, H., Alavi, S. N., Von Gunten, H. R. \& Ergin, M. (1989). Superficial deep-water sediments of the Eastern Marmara basin. Geo-Marine Lett., 9, 27-36.

Guinasso, N. L. Jr \& Schink, D. R. (1975). Quantitative estimates of biological mixing rates in abyssal sediments. J. Geophys. Res., 80, 3032-43.

Koreneva, E. V. (1971). Spores and pollen in Mediterranean bottom sediments. In The Micropaleontology of Oceans, Eds B. M. Funnel \& W. R. Riedel, Cambridge University Press, London, pp. 361-71.

Miller, A. G. (1983). Mediterranean Sea physical aspects. In Estuaries and Enclosed Seas (Ecosystem of the World, 26), Ed. B. H. Ketchum. Elsevier, Amsterdam, pp. 219-31.

Robbins, J. A. \& Edgington, D. N. (1975). Determination of recent sedimentation rates in Lake Michigan using Pb-210 and Cs-137. Geochim. Cosmochim. Acta, 39, 285-304. 
Robbins, J. A., Krezoski, J. R. \& Mozley, S. C. (1977). Radioactivity in sediments of the Great Lakes: post depositional redistribution by deposit-feeding organisms. Earth Planet. Sci. Lett., 36, 325-33.

Smith, J. N. \& Walton, $\Lambda$. (1980). Sediment accumulation rates and geochronologies measured in the Saguenay Fjord using the $\mathrm{Pb}-210$ dating method. Geochim. Cosmochim. Acta, 44, 225.

Stanley, D. J. \& Blanpied, C. (1980). Late Quaternary water exchange between the eastern Mediterranean and the Black Sea. Nature, 285, 537-41. 